\title{
A Biblioteca de Babel ainda não foi destruída. Para uma educação à literatura
}

\author{
Biagio D'Angelo • \\ Universidad Pázmany Péter de Budapest, \\ Hungría - Asociación Internacional de \\ Literatura Comparada
}

\begin{abstract}
Resumo
Esse artigo propóe questionar não apenas o "estatuto" da literature hoje, mas também a possibilidade de dedicar um espaço especifico e amplo ao estudo do fenômeno literário. As propostas que aqui são apresentadas configuram a exigência de uma educação à literatura e à cultura, cuja ausência é um dos problemas críticos da época da globalização.
\end{abstract}

\section{Palavras-chave:}

estatuto da literatura · educação à cultura · Literatura comparada

\begin{abstract}
This paper starts with a question concerning not just the "status" of literature today, but concerning the "reasonability" of consecrating a specific, wide space to the study of literature. The proposals, here presented, configure the exigence of an education to literature and culture, whose lack is one of the critical problems of globalized times.
\end{abstract}

\section{Key-words:}

status of literature - education to culture - Comparative literature

\footnotetext{
- Magíster en Lenguas y Literaturas Extranjeras por la Università Ca Foscari de Venezia (1992) y Doctor en Letras por la Universidad Rusa de Estudios Humanísticos (1998).

Ex Presidente del Comité Internacional de Estudios Latino-americanos (2007-2010) de AILC/ICLA (Asociación Internacional de Literatura Comparada) y miembro de Abralic (Associação Brasileira de Literatura Comparada). Se ha desempeñado como profesor en la Universidad Católica Sedes Sapientiae de Lima (Perú) y en la Pontificia Universidad Católica de São Paulo, Brasil. Actualmente se desempeña como profesor en la Universidad Pázmany Péter de Budapest, Hungría.

Ha dictado cursos y conferencias en Universidad Católica de Buenos Aires, Universidad Nacional del Litoral y Católica de Santa Fe (Argentina); Nacional de Bogotá (Colombia); Sorbonne de Paris, Francia; Universidade Alberta de Lisboa, Portugal.

Entre sus publicaciones más recientes se destacan: Las babas del sabio. Ensayos sobre la dislocación de la escritura (Lima, 2008); Trangresiones y tradiciones en la literatura (coautor Jorge Puccinelli, Lima, 2009) y Comparaciones en vertical. Conflictos mitológicos en las literaturas de las Américas (coautor con Paola Mildonian, Venezia, 2009).
} 